\title{
Disparities of Immunotherapy Utilization in Patients with Stage III Cutaneous Melanoma: A National Perspective
}

\author{
ZAID AL-QURAYSHI, JASON E. CROWTHER, JOHN B. HAMNER, \\ CHRISTOPHER DUCOIN, MARY T. KILLACKEY and EMAD KANDIL
}

Department of Surgery, Tulane University School of Medicine, New Orleans, LA, U.S.A.

\begin{abstract}
Background/Aim: Immunotherapy combined with surgery is associated with better survival than surgery alone in patients with advanced melanoma. This study examined the utilization of immunotherapy in relation to population characteristics and the associated survival benefit. Materials and Methods: This was a retrospective cohort study utilizing the US National Cancer Database. The study population included 6,165 adult patients ( $\geq 18$ years) with stage III cutaneous melanoma (median follow-up=32 months). Results: A total of 1,854 patients underwent immunotherapy in addition to surgery, which was associated with a survival benefit over surgery alone (hazard ratio $(H R)=0.66,95 \%$ confidence interval $(C I)=0.56-0.77, p<0.001)$. Older age, presence of comorbidities, Medicaid/Medicare insurance, and living in a community with lower average education level were associated with less immunotherapy utilization (all $p<0.05$ ). No statistically significant racial disparity in immunotherapy usage was found $(p=0.07)$. Conclusion: Compared to other demographic factors, insurance status was associated with the greatest disparities in immunotherapy utilization and mortality for patients who underwent surgery for advanced melanoma.
\end{abstract}

Cutaneous melanoma is the fifth most commonly diagnosed cancer in the United States and the most deadly form of skin cancer, with 76,000 new cases diagnosed and over 10,000 deaths in 2016 (1). Although the annual incidence of cutaneous melanoma has shown a steady increase, 14 per 100,000 in 1992 to 23 per 100,000 in 2014 , the mortality rate has remained fairly stable $(2.6-2.8$ per 100,000$)$ over the same period (2).

Although efforts at earlier detection and improved treatment regimens have improved survival and reduced

Correspondence to: Emad Kandil, Tulane Medical School, Department of Surgery \#8622, 1430 Tulane Avenue, New Orleans, LA 70112-2699, USA. Tel: +1 5049887407, Fax: +1 5047547846, e-mail: ekandil@tulane.edu

Key Words: Melanoma, health disparities, immunotherapy. recurrence of melanoma, these improvements have not been equally distributed among the population. Patients who come from more vulnerable populations typically have worse outcomes, due to a combination of poorer health education, less access to primary health care, and less access to both standard and novel treatment modalities $(3,4)$. Similar poorer outcomes for certain patient groups are found for patients diagnosed with melanoma, with studies identifying factors such as lack of patient education regarding melanoma risk, lack of insurance or Medicaid ( $v s$. private) insurance, and lack of access to dermatological specialists (5-8).

The aim of the current study was to assess disparities in treatment of cutaneous melanoma in the United States based upon patient characteristics. In order to avoid differences in initial presentation, we limited our study to those who presented with stage III cutaneous melanoma. The consensus of specialists involved in melanoma treatment is that most cases of stage III melanoma should be treated with a combination of surgical resection of the primary lesion with adjuvant immunotherapy to eliminate any residual micrometastases (9). This study sought to assess which demographic groups demonstrated differences in treatment modalities, and whether differences in treatment modalities translated into differences in survival outcomes.

\section{Materials and Methods}

The study was a retrospective cohort study utilizing the US National Cancer Database (NCDB), 2004-2012, which is a nationwide, facility-based, comprehensive clinical surveillance resource oncology set of de-identified data that currently captures $70 \%$ of all newly diagnosed malignancies in the US annually (10). The study population included adult patients ( $\geq 18$ years) newly diagnosed with primary stage III (T1a-4b, N1a-3, M0) cutaneous melanoma and who underwent excisional surgery of the primary tumor site. The study population was classified into those who receive immunotherapy and those who did not.

The main study outcomes were the associations between utilization of immunotherapy (primarily interferon), overall survival, and various patient characteristics (demographic, socioeconomic, and clinical). Specifications and attributes of the variables considered in the analysis included: (i) Demographic factors: age $(<45,45-<65$, $\geq 65$ years), gender, race; (ii) Socioeconomic factors: insurance (none, 
private, Medicaid, Medicare), community household income and high school graduation rates (both factors estimated from patient zip code and the American Community Survey data); (iii) Clinical factors: stage (IIIA, IIIB, IIIC), Charlson/Deyo Comorbidity score $(0,1, \geq 2)(11)$, chemotherapy utilization, lymph node biopsy, type of treating hospital (community, academia/research, other). All variables were checked for completeness.

Chi-square test and cross-tabulation were performed in the assessment of association between each of the independent factors and immunotherapy status. Log-rank test and Kaplan-Meier curves were used to assess overall survival in association with the independent factors. Factors that demonstrated significant association were included in the multivariate Cox hazard models. Cox hazard models were used to assess time interaction and calculate hazard ratio (HR) and $95 \%$ confidence interval $(95 \% \mathrm{CI})$, while logistic regression was used to calculate odds ratios (OR) and 95\% CI to assess disparities in immunotherapy utilization. Statistical level was set as $\alpha=0.05$, and all statistical analysis were performed using SAS software version 9.3 (SAS Institute Inc., Cary, NC, USA).

\section{Results}

A total of 6,165 patients with stage III cutaneous melanoma were included (Table I). The mean age of the study population was $60.9( \pm 12.7)$ years. The median follow-up time was 32.0 (interquartile range: 18.4-55.3) months. The vast majority of the study sample were White (97.4\%), and males formed $62.4 \%$ of the sample. Slightly more than half $(55.8 \%)$ of the study population had private insurance. A total of 2,387 $(38.7 \%)$ patients presented with stage IIIA, while patients with stages IIIB and IIIC represented $37.6 \%$ and $23.7 \%$, respectively. Immunotherapy was used in 1,854 $(30.1 \%)$ patients, and chemotherapy was used in $465(7.5 \%)$. Overall mortality risk in the study population was $42.6 \%$.

Likelihood of immunotherapy differed across several of the groups (Table II). Immunotherapy was most likely to be administrated to younger patients and those with no comorbidities $(p<0.05$ each). Patients with stage IIIA were less likely to receive immunotherapy than patients with stage IIIB $(p<0.001)$, while there was no significant difference in the utilization of immunotherapy between patients with stages IIIB and IIIC $(p=0.18)$. The utilization of immunotherapy under Medicaid and Medicare health coverage was significantly lower compared to private insurance ( $p=0.003$ and $p<0.001$, respectively). Furthermore, patients living in communities of low education level were less likely to receive immunotherapy $(p<0.05)$. There were no statistically significant racial disparities in terms of overall survival and utilization of immunotherapy found, but there was very little racial variation within the population.

Overall, patients who received immunotherapy had significantly better survival than patients who did not $[p<0.001]$, and there were also group differences in this measure (Table III). Other clinical factors that demonstrated improved survival included stage IIIA, no or one
Table I. Descriptive statistics of the study population in relation to management type.

\begin{tabular}{|c|c|c|c|c|}
\hline \multirow[b]{2}{*}{ Factor } & \multirow[b]{2}{*}{$\begin{array}{c}\text { All cases } \\
(\%) \\
(\mathrm{N}=6,165)\end{array}$} & \multicolumn{3}{|c|}{ Management (\%) } \\
\hline & & $\begin{array}{c}\text { Surgery } \\
\text { only } \\
(\mathrm{N}=4,311)\end{array}$ & $\begin{array}{c}\text { Surgery }+ \\
\text { immunotherapy } \\
(\mathrm{N}=1,854)\end{array}$ & $p$-Value ${ }^{\mathrm{a}}$ \\
\hline \multicolumn{5}{|l|}{ Age (years) } \\
\hline$<45$ & 9.6 & 7.6 & 14.5 & \\
\hline $45-<65$ & 54.1 & 47.1 & 70.3 & \\
\hline$\geq 65$ & 36.3 & 45.4 & 15.2 & $<0.001$ \\
\hline \multicolumn{5}{|l|}{ Gender } \\
\hline Male & 62.4 & 62.4 & 62.5 & \\
\hline Female & 37.6 & 37.7 & 37.5 & 0.94 \\
\hline \multicolumn{5}{|l|}{ Race } \\
\hline White & 97.4 & 97.0 & 98.3 & \\
\hline Black & 1.2 & 1.5 & 0.6 & \\
\hline Hispanic & 0.2 & 0.1 & 0.2 & \\
\hline Other & 1.2 & 1.4 & 1.0 & 0.017 \\
\hline \multicolumn{5}{|l|}{ Charlson/Deyo score } \\
\hline 0 & 84.0 & 82.6 & 87.4 & \\
\hline 1 & 13.3 & 14.2 & 11.4 & \\
\hline$\geq 2$ & 2.6 & 3.2 & 1.2 & $<0.001$ \\
\hline \multicolumn{5}{|l|}{ TNM stage } \\
\hline IIIA & 38.7 & 38.4 & 39.4 & \\
\hline IIIB & 37.6 & 36.7 & 39.8 & \\
\hline IIIC & 23.7 & 24.9 & 20.8 & 0.002 \\
\hline \multicolumn{5}{|l|}{ Chemotherapy } \\
\hline No & 92.5 & 91.2 & 95.4 & \\
\hline Yes & 7.5 & 8.8 & 4.6 & $<0.001$ \\
\hline \multicolumn{5}{|l|}{ Regional LN biopsy } \\
\hline No & 3.0 & 3.7 & 1.2 & \\
\hline Yes & 97.0 & 96.3 & 98.8 & $<0.001$ \\
\hline \multicolumn{5}{|l|}{ Insurance } \\
\hline None & 4.7 & 4.5 & 5.1 & \\
\hline Private & 55.8 & 47.9 & 74.0 & \\
\hline Medicaid & 3.6 & 3.6 & 3.6 & \\
\hline Medicare & 34.9 & 43.0 & 16.0 & \\
\hline Other & 1.1 & 1.0 & 1.3 & $<0.001$ \\
\hline \multicolumn{5}{|l|}{ Household income } \\
\hline $\begin{array}{l}\text { quartileb }^{b} \\
\text { 2nd }\end{array}$ & $\begin{array}{r}1 \mathrm{st} \\
21.2\end{array}$ & $\begin{array}{l}12.1 \\
21.3\end{array}$ & $\begin{array}{l}12.6 \\
20.8\end{array}$ & 10.9 \\
\hline $3 \mathrm{rd}$ & 27.6 & 27.4 & 28.2 & \\
\hline 4 th & 39.1 & 38.7 & 40.1 & 0.22 \\
\hline \multicolumn{5}{|l|}{$\begin{array}{l}\text { HS graduation } \\
\text { rate quartileb }\end{array}$} \\
\hline $1 \mathrm{st}$ & 12.3 & 13.4 & 9.6 & \\
\hline 2nd & 22.9 & 23.3 & 21.8 & \\
\hline $3 \mathrm{rd}$ & 30.7 & 30.1 & 32.1 & \\
\hline 4th & 34.2 & 33.2 & 36.5 & $<0.001$ \\
\hline \multicolumn{5}{|l|}{ Hospital type } \\
\hline Community & 41.3 & 41.2 & 41.4 & \\
\hline Academic/research & 52.8 & 52.8 & 52.6 & \\
\hline Other & 6.0 & 5.9 & 6.0 & 0.99 \\
\hline
\end{tabular}

LN, Lymph node; HS, high school. ${ }^{a}$ Chi-square test. ${ }^{b}$ By matching the zip code of the patient at the time of diagnosis.

comorbidity, and the performance of regional lymph node biopsy ( $p<0.05$ each). Additionally, younger age ( $<65$ years), female gender, and private insurance were all associated with better overall survival ( $p<0.05$ each). 
Table II. Adjusted odds ratios (OR) for the probability of being administered immunotherapy for patients with stage III cutaneous melanoma. $(N=6,165)$.

\begin{tabular}{|c|c|c|c|c|}
\hline Factor & $\begin{array}{c}\text { Received } \\
\text { immunotherapy } \\
(\%)\end{array}$ & $\mathrm{aOR}^{\mathrm{a}}$ & $95 \% \mathrm{CI}$ & $p$-Value \\
\hline \multicolumn{5}{|l|}{ Age (years) } \\
\hline$<45$ & 45.1 & Reference & & \\
\hline $45-<65$ & 39.1 & 0.77 & $0.64-0.92$ & 0.004 \\
\hline$\geq 65$ & 12.6 & 0.24 & $0.18-0.31$ & $<0.001$ \\
\hline \multicolumn{5}{|l|}{ Gender } \\
\hline Male & 30.1 & Reference & & \\
\hline Female & 30.0 & 1.02 & $0.90-1.15$ & 0.77 \\
\hline \multicolumn{5}{|l|}{ Race } \\
\hline White & 30.3 & Reference & & \\
\hline Black & 14.7 & 0.53 & $0.27-1.04$ & 0.07 \\
\hline Hispanic & 33.3 & 1.16 & $0.27-4.92$ & 0.84 \\
\hline Other & 23.7 & 0.78 & $0.45-1.36$ & 0.39 \\
\hline \multicolumn{5}{|c|}{ Charlson/Deyo score } \\
\hline 0 & 31.3 & 1.72 & $1.08-2.74$ & 0.02 \\
\hline 1 & 25.7 & 1.62 & $0.997-2.65$ & $5 \quad 0.05$ \\
\hline$\geq 2$ & 14.2 & Reference & & \\
\hline \multicolumn{5}{|l|}{ TNM stage } \\
\hline IIIA & 30.6 & 0.80 & $0.70-0.91$ & $<0.001$ \\
\hline IIIB & 31.8 & Reference & & \\
\hline IIIC & 26.4 & 0.90 & $0.77-1.05$ & 0.18 \\
\hline \multicolumn{5}{|l|}{ Insurance } \\
\hline None & 32.8 & 0.69 & $0.53-0.90$ & 0.006 \\
\hline Private & 39.9 & Reference & & \\
\hline Medicaid & 29.9 & 0.63 & $0.47-0.86$ & 0.003 \\
\hline Medicare & 13.8 & 0.62 & $0.50-0.77$ & $<0.001$ \\
\hline \multicolumn{5}{|c|}{$\begin{array}{l}\text { Household income } \\
\text { quartileb }\end{array}$} \\
\hline $1 \mathrm{st}$ & 27.0 & 1.27 & $0.99-1.62$ & 0.06 \\
\hline 2nd & 29.6 & 1.18 & $0.98-1.43$ & 0.08 \\
\hline 3 rd & 30.7 & 1.13 & $0.96-1.33$ & 0.13 \\
\hline 4th & 30.9 & Reference & & \\
\hline \multicolumn{5}{|c|}{$\begin{array}{l}\text { HS graduation rate } \\
\text { quartileb }^{b}\end{array}$} \\
\hline $1 \mathrm{st}$ & 23.4 & 0.59 & $0.45-0.76$ & $<0.001$ \\
\hline 2nd & 28.7 & 0.80 & $0.66-0.97$ & 0.02 \\
\hline $3 \mathrm{rd}$ & 31.5 & 0.94 & $0.80-1.10$ & 0.43 \\
\hline 4th & 32.1 & Reference & & \\
\hline
\end{tabular}

aOR, Adjusted odd ratio; CI, confidence interval; LN, lymph node; HS high school. aThe models included: age, gender, race, Charlson/Deyo score, stage, insurance, household income, and education level. bBy matching the zip code of the patient at the time of diagnosis.

\section{Discussion}

The main objective of this study was to identify sociological factors related to differences in melanoma treatment and outcomes. We sought to accomplish this by primarily focusing on patients with an initial diagnosis of stage III melanoma, and analyzing what factors were related to the likelihood of immunotherapy utilization and subsequent
Table III. Multivariate Cox hazard ratios of mortality risk for selected factors in patients with stage III cutaneous melanoma $(N=6,165)$.

\begin{tabular}{|c|c|c|c|}
\hline Factor & $\mathrm{aHR}^{\mathrm{a}}$ & $95 \% \mathrm{CI}$ & $p$-Value \\
\hline \multicolumn{4}{|l|}{ Age (years) } \\
\hline$<45$ & Reference & & \\
\hline $45-<65$ & 1.08 & $0.90-1.31$ & 0.40 \\
\hline$\geq 65$ & 1.75 & $1.33-2.30$ & $<0.001$ \\
\hline \multicolumn{4}{|l|}{ Gender } \\
\hline Male & Reference & & \\
\hline Female & 0.77 & $0.70-0.83$ & $<0.001$ \\
\hline \multicolumn{4}{|l|}{ Race } \\
\hline White & Reference & & \\
\hline Black & 1.32 & $0.98-1.78$ & 0.07 \\
\hline Hispanic & 1.44 & $0.54-3.84$ & 0.47 \\
\hline Other & 0.94 & $0.66-1.35$ & 0.75 \\
\hline \multicolumn{4}{|c|}{ Charlson/Deyo score } \\
\hline 0 & 0.59 & $0.49-0.72$ & $<0.001$ \\
\hline 1 & 0.69 & $0.56-0.86$ & $<0.001$ \\
\hline$\geq 2$ & Reference & & \\
\hline \multicolumn{4}{|l|}{ TNM stage } \\
\hline IIIA & 0.38 & $0.33-0.44$ & $<0.001$ \\
\hline IIIB & Reference & & \\
\hline IIIC & 2.45 & $2.19-2.74$ & $<0.001$ \\
\hline \multicolumn{4}{|c|}{ Immunotherapy } \\
\hline No & Reference & & \\
\hline Yes & 0.66 & $0.56-0.77$ & $<0.001$ \\
\hline \multicolumn{4}{|c|}{ Chemotherapy } \\
\hline No & Reference & & \\
\hline Yes & 1.53 & $1.21-1.93$ & $<0.001$ \\
\hline \multicolumn{4}{|c|}{ Regional LN biopsy } \\
\hline No & Reference & & \\
\hline Yes & 0.73 & $0.54-0.99$ & 0.04 \\
\hline \multicolumn{4}{|l|}{ Insurance } \\
\hline None & 1.27 & $1.06-1.53$ & 0.01 \\
\hline Private & Reference & & \\
\hline Medicaid & 1.48 & $1.21-1.81$ & $<0.001$ \\
\hline Medicare & 1.22 & $1.07-1.40$ & 0.003 \\
\hline \multicolumn{4}{|c|}{ Household income quartileb } \\
\hline $1 \mathrm{st}$ & 1.05 & $0.90-1.23$ & 0.51 \\
\hline 2nd & 1.06 & $0.94-1.21$ & 0.34 \\
\hline $3 \mathrm{rd}$ & 1.01 & $0.91-1.13$ & 0.84 \\
\hline 4 th & Reference & & \\
\hline \multicolumn{4}{|c|}{ HS graduation rate quartileb } \\
\hline 1 st & 1.21 & $0.97-1.52$ & 0.10 \\
\hline 2nd & 1.08 & $0.91-1.28$ & 0.36 \\
\hline $3 \mathrm{rd}$ & 1.09 & $0.97-1.23$ & 0.16 \\
\hline 4 th & Reference & & \\
\hline
\end{tabular}

aHR, Adjusted hazard ratio; CI, confidence interval; LN, lymph node; HS; high school. aThe models included: age, gender, race, Charlson/Deyo score, stage, immunotherapy status, chemotherapy status, regional lymph node surgery status, insurance, household income, and education level. ${ }^{b}$ By matching the zip code of the patient at the time of diagnosis.

mortality. A secondary objective was analyzing which demographic and clinical factors were related to immunotherapy utilization and mortality. 
Overall, it was found that the likelihood of receiving immunotherapy was associated with several background variables of patients - including demographic factors such as age, insurance status, community income and education, as well as clinical factors such as melanoma staging and presence of comorbidities. In terms of mortality, this study produced similar data to those found in clinical trials, namely that adjuvant immunotherapy combined with surgery was associated with better survival outcomes than surgery alone for patients with initial diagnosis of stage III cutaneous melanoma $(12,13)$.

Of particular interest were patient variables showing parallel results in both rate of immunotherapy administration and mortality, as these might reflect disparities in the use of immunotherapy. Patient variables showing parallels in both immunotherapy usage and mortality included age, presence of comorbidities, TMN stage, and insurance status. Younger patients, those with fewer comorbidities, and those with private insurance were both more likely to receive immunotherapy and had better survival rates. Only TMN stage showed an opposing pattern, with those having higher staging classification being more likely to receive immunotherapy but less likely to survive.

The findings regarding age and the number of comorbidities may not reflect inequalities in the availability of treatment, but instead decisions with different risk-to-benefit ratios. Immunotherapy can be associated with a range of side-effects, from mild to serious (14). Immunotherapy side-effects are more likely to occur, and more likely to be severe when they do occur, in older patients and those with multiple comorbidities. Regardless of treatment modality, older patients and those with more comorbidities have poorer outcomes following diagnosis. Thus, differences in utilization of immunotherapy by age or comorbidity, rather than reflecting a social disparity, may instead reflect a different risk-to-benefit calculus appropriate to these patients.

Some differences by insurance status in the rate of immunotherapy utilization can also be explained by similar reasoning. Those patients who were on Medicare were almost exclusively in the over 65-year-old age group, and thus the decreased utilization of immunotherapy in these patients could be related to their age rather than Medicare insurance per se. The same cannot be said, however, for those with Medicaid insurance or without insurance altogether. Patients with Medicaid insurance or without insurance would not necessarily be sicker than those with private insurance, although they may be, but they are almost certainly of a lower socioeconomic class as compared to those with private insurance and on average compared to those with Medicare insurance. Another notable finding is that even though those on Medicare were less likely to receive immunotherapy than those on Medicaid, it was the Medicaid patients who actually appeared to have higher mortality. This is especially remarkable given the much smaller likelihood of older patients receiving immunotherapy at all, and the greater mortality associated with age. Thus, even though Medicaid patient were over twice as likely to receive adjuvant immunotherapy, they nevertheless had higher mortality.

There were also some variables showing divergence in their relationship to immunotherapy utilization and mortality, with these variables including gender, community income level, and high school graduation rate. Although both men and women underwent adjuvant immunotherapy at similar rates, mortality was significantly less for women as compared to men. The gender disparity in mortality is consistent with other studies which have found similar differences, although it is not completely clear whether the basis for this difference is biological or cultural in nature (15, 16). Community variables, average community income and educations level, have been found to be related to likelihood of cancer diagnosis and cancer outcomes $(3,5)$. In the current study, even though it was found that patients from communities with lower average income and lower education levels were less likely to receive adjuvant immunotherapy, this did not translate into differences in mortality.

\section{Conclusion}

The current study included patients who presented initially with diagnosis of stage III cutaneous melanoma and examined the relationship between patient characteristic variables (demographic, socioeconomic, and clinical), the likelihood of adjuvant immunotherapy, and how this was associated with mortality outcomes. Patients were less likely to receive immunotherapy when there were plausible contraindications to therapy based upon risk-to-benefit. There were notable differences in whether patients received immunotherapy based upon socioeconomic factors such as insurance status and community factors such as average wealth and education status of the community. However, of these socioeconomic factors, only insurance status (Medicaid or no insurance) translated into worse outcomes in terms of mortality. Insurance status thus appears to be a significant contributing factor to disparities in healthcare delivery and outcomes in the case of stage III cutaneous melanoma.

\section{Funding}

This research did not receive any specific grant from funding agencies in the public, commercial, or not-for-profit sectors.

\section{References}

1 Siegel RL, Miller KD and Jemal A: Cancer Statistics, 2016. CA Cancer J Clin 66: 7-30, 2016. 
2 SEER Cancer Stat Facts: Melanoma of the Skin. National Cancer Institute, Bethesda, MD. http://seer.cancer.gov/ statfacts/html/melan.html

3 Krieger N, Emmons KM and Williams D: Chapter 1: Defining, investigating, and addressing cancer inequities: Critical issues. In: Towards the Elimination of Cancer Disparities. Howard K. Koh (ed.). New York: Springer, pp. 3-28, 2009.

4 Du XL, Lin CC, Johnson NJ and Altekruse S: Effects of individual-level socioeconomic factors on racial disparities in cancer treatment and survival. Cancer 117(14): 3242-3251, 2011

5 Aoki CA, Geller A and Chen MS: Chapter 10: Melanoma and primary hepatocellular carcinoma. In: Towards the Elimination of Cancer Disparities. Howard K. Koh (ed.). New York: Springer, pp. 227-256, 2009.

6 Xavier MH, Drummond-Lage AP and Baeta C, Rocha L, Almeida AM and Wainstein AJ: Delay in cutaneous melanoma diagnosis: Sequence analyses from suspicion to diagnosis in 211 patients. Medicine 95(31): e4396, 2016.

7 Amini A, Rusthoven CG, Waxweiler TV, Jones BL, Fisher CM, Karam SD and Raben D: Association of health insurance with outcomes in adults ages 18 to 64 years with melanoma in the United States. J Am Acad Dematol 74(2): 309-316, 2016.

8 Roetzheim RG, Pal N, van Durme DJ, Wathington D, Ferrante JM, Gonzalez EC and Krischer JP: Increasing supplies of dermatologists and family physicians are associated with earlier stage of melanoma detection. J Am Acad Dermatol 43: 211-218, 2000 .

9 Kaufman HL, Kirkwood JM, Hodi FS, Agarwala S, Amatruda T, Bines SD, Clark JI, Curti B, Ernstoff MS, Gajewski T, Gonzalez R, Hyde LJ, Lawson D, Lotze M, Lutzky J, Margolin K, McDermott DF, Morton D, Pavlick A, Richards JM, Sharfman W, Sondak VK, Sosman J, Steel S, Tarhini A, Thompson JA, Titze J, Urba W, White R and Atkins MB: The Society for Immunotherapy of Cancer consensus statement on tumour immunotherapy for the treatment of cutaneous melanoma. Nat Rev Clin Oncol 10(10): 588-598, 2013.

10 American college of surgeons. National cancer database. https://www.facs.org/quality-programs/cancer/ncdb. Updated 2015. Accessed 2015.
11 Deyo RA, Cherkin DC and Ciol MA: Adapting a clinical comorbidity index for use with ICD-9-CM administrative databases. J Clin Epidemiol 45: 613-619, 1992.

12 Eggermont AM, Chiarion-Sileni V and Grob JJ, Dummer R, Wolchok JD, Schmidt H, Hamid O, Robert C, Ascierto PA, Richards JM, Lebbe C, Ferraresi V, Smylie M, Weber JS, Maio M, Konto C, Hoos A, de Pril V, Gurunath RK, de Schaetzen G, Suciu S and Testori A: Adjuvant ipilimumab versus placebo after complete resection of high-risk stage III melanoma (EORTC 18071): a randomised, double-blind, phase 3 trial. Lancet Oncol 16: 522-530, 2015.

13 Mocellin S, Pasquali S, Rossi CR and Nitti D: Interferon alpha adjuvant therapy in patients with high-risk melanoma: a systematic review and meta-analysis. J Natl Cancer Inst 102: 493-501, 2010.

14 Bilir SP, Ma QF, Zhao ZY, Wehler E, Munakata J and Barber B: Economic burden of toxicities associated with treating metastatic melanoma in the United States. Am Health Drug Benefits 9(4): 203-213, 2016.

15 Lasithiotakis K, Leiter U, Meier F, Eigentler T, Metzler G, Moehrle M, Breuninger $\mathrm{H}$ and Garbe $\mathrm{C}$ : Age and gender are significant independent predictors of survival in primary cutaneous melanoma. Cancer 112(8): 1795-1804, 2008.

16 Scoggins CR, Ross MI, Reintgen DS, Noyes RD, Goydos JS, Beitsch PD, Urist MM, Ariyan S, Sussman JJ, Edwards MJ, Chagpar AB, Martin RC, Stromberg AJ, Hagendoorn L and McMasters KM: Sunbelt Melanoma Trial. Gender-related differences in outcome for melanoma patients. Ann Surg 243(5): 693-698, 2006.
Received January 29, 2018

Revised March 8, 2018

Accepted March 15, 2018 